\title{
Williams Syndrome With Rare Ureteric Abnormality
}

\author{
Jaffar Khan ${ }^{1}$, Khaleel I. Al-obaidy ${ }^{1}$, Rong Fan ${ }^{1}$ \\ 1. Pathology and Laboratory Medicine, Indiana University School of Medicine, Indianapolis, USA
}

Corresponding author: Jaffar Khan, khanja@iu.edu

\begin{abstract}
Williams syndrome (WS), also known as Williams-Beuren syndrome, is a rare genetic disorder characterized by infantile hypercalcemia, short stature, a varying degree of mental retardation, elfin-like facial features, and cardiovascular abnormalities, including systemic hypertension, aortic hypoplasia, coarctation of the aorta, and valvular heart disease (aortic and pulmonic stenosis, mitral valve prolapsed or bicuspid aortic valve). It is also characterized by friendly and outgoing personality. The majority of WS cases are sporadic, while few are familial. Both sporadic and familial cases are due to deletion of chromosome 7 (7q11.23). Herein, we present an autopsy case of a 16-day-old male infant born to a 25 -year-old mother with a history of William syndrome. Prenatal echocardiogram showed supravalvular aortic stenosis and pulmonary stenosis. The postnatal course was complicated by feeding difficulties and desaturation. Gross autopsy findings included generalized edema, macrocephaly with short neck, and multiple facial anomalies (mandibular hypoplasia, depressed nasal bridge, long philtrum, ear malformation, and wide mouth). The heart was hypertrophied with obstructed ventricles and rudimentary, hypoplastic aortic root. An enlarged, dilated, and tortuous left ureter was a unique finding to this case, in addition to variation in the renal arteries' size and an small bowel outpouching located $33 \mathrm{~cm}$ from the ileocecal valve. Cytogenetic analysis revealed deletion of chromosome 7 (7q11.23). In conclusion, majority of WS cases are sporadic, and few are familial and are inherited as autosomal dominant.
\end{abstract}

Categories: Pathology

Keywords: william's syndrome, tortuous ureter, connective tissue, cardiovascular, autopsy

\section{Introduction}

Williams syndrome (WS) is characterized by typical elfin likefacies, puffiness around the eyes, short nose and full lips, growth delays, mental retardation, extroverted personality, and congenital heart defects such as supravalvular aortic stenosis [1]. The real frequency of this syndrome is unknown, although it is estimated to be 1 in 10,000-50,000 live births [2]. WS is caused by deletion of genes of chromosome 7q11.23, which codes for elastin. It affects $1 / 10,000$ people. Patients with this disease have increased morbidity and mortality, mostly due to cardiovascular complications [3]. The cardiovascular issues could be due to elastin deficiency and increased cellular proliferation in the vessel wall with the subsequent development of

Review began 07/15/2021 Review ended 08/12/2021 Published 08/16/2021

\section{() Copyright 2021}

Khan et al. This is an open access article distributed under the terms of the Creative Commons Attribution License CC-BY 4.0., which permits unrestricted use, distribution, and reproduction in any medium, provided the original author and source are credited. obstructive lesions [4]. Since WS's first description, medical treatment has been refined for the condition, but mental health treatment has not been fully addressed. Therapeutic interventions for language, cognition, and behavior will have to be designed and tested [5].

This article was previously presented as a meeting abstract at the College of American Pathologists 2020 Annual Meeting (CAP20 Virtual) on September 9, 2020.

\section{Case Presentation}

The decedent was a 16-day-old male infant, born at 39 weeks (clinical gestational age determined by second prenatal ultrasound) via cesarean section with no labor complications, to a 25 -year-old female. The decedent's mother had history of WS. The mother had appropriate prenatal care prior to delivery and had history of hypertension, asthma, and obesity. Prenatal echocardiogram showed supravalvular aortic stenosis and branch pulmonary stenosis. Apgar score at 1 and 5 minutes was 6 and 8, respectively. The initial saturations were below expected levels and he was placed on continuous positive airway pressure (CPAP). The patient was then transferred to the neonatal intensive care unit. Cytogenetics of the decedent showed deletion of 7q11.23, which is associated with WS. He was weaned off of CPAP but he continued to have feeding difficulties and most of his feeding was through nasogastric tube. On day 14 his heart rate dropped to $50 \mathrm{bpm}$. He was then intubated and chest compressions were started but unfortunately the patient passed away. Autopsy gross examination revealed significant dysmorphology externally. Dysmorphological evaluation revealed generalized body swelling (anasarca), macrocephaly with shortened neck, hypoplasia of the mandible, depressed nasal bridge, fullness of the midface, long philtrum, wide mouth, puffiness around the eyes and lips, malformed external normally set ears, and shortened and hypertrophied tongue (Figure 1). Along with these features the decedent cytogenetics test showed 7q11.23 gene deletion, which is associated with WS. The heart weighs $34.2 \mathrm{~g}$ (expected $20.4 \mathrm{~g}$ ). The great vessels entered and exit the heart in the usual 


\section{Cureus}

manner, and a normal innominate vein was identified. The epicardial coronary arteries were normally distributed, and the right and left coronary arteries were poorly visualized. The aortic arch was left-sided with the usual branching pattern. There were two extracorporeal membrane oxygenation lines in the vessels of the neck (carotids). There was narrowing of aorta before the aortic arch. There was hypoplasia of the aortic root, and the aortic valve was very rudimentary, suggesting of supravalvular aortic stenosis. The ductus arteriosus was widely patent as expected. The heart was opened in the direction of blood flow. The cardiac chambers were normally related, there was left ventricular and right ventricular hypertrophy, and the right and left ventricular cavities or chambers were very small due to hypertrophied ventricles. There were no atrial or ventricular septal defects. The foramen ovale was normally formed, and the flap valve of the foramen ovale appears competent. The cardiac valves were unremarkable. The important findings were an enlarged tortuous left ureter (Figure 2).

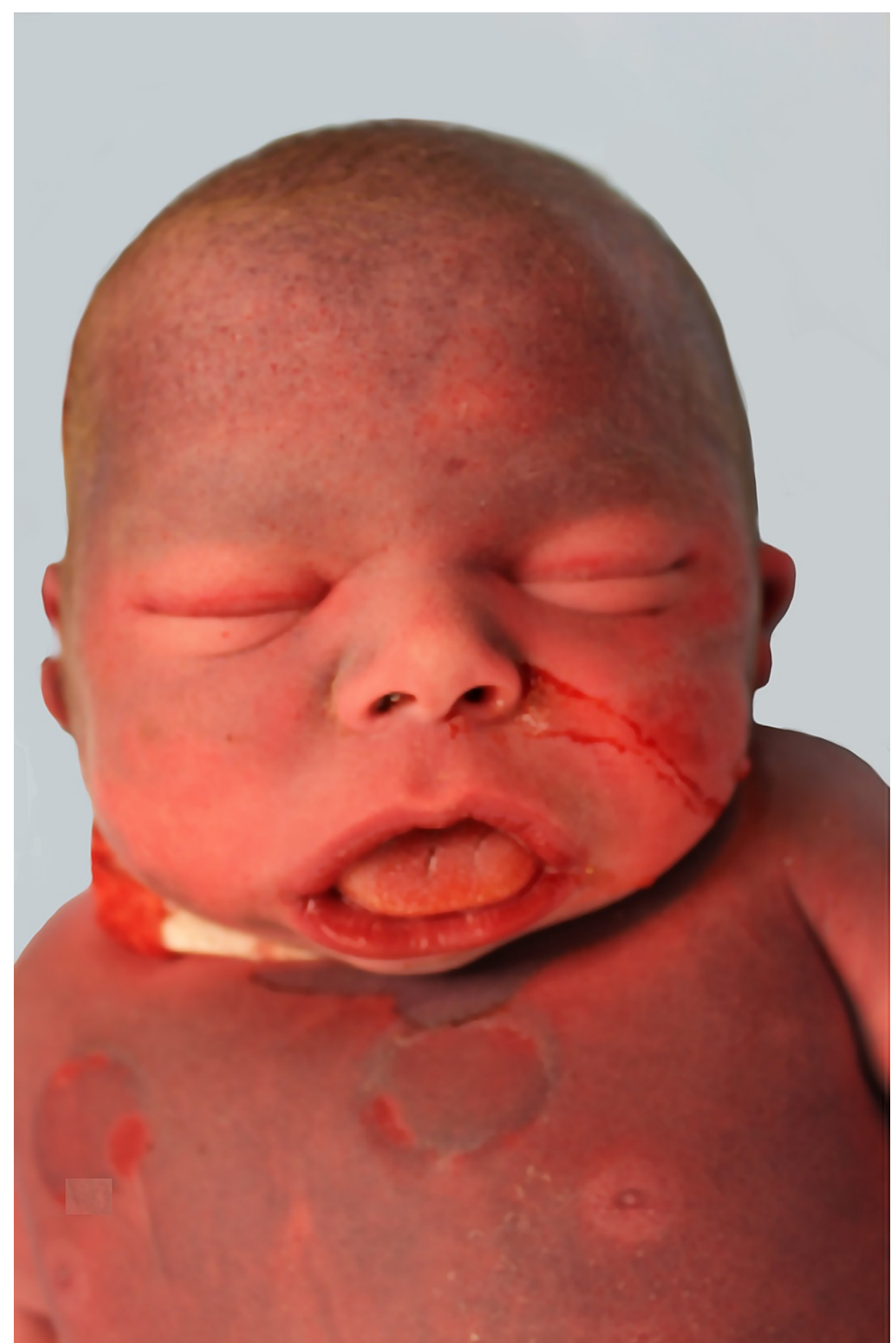

FIGURE 1: Puffiness around the eyes, short nose 


\section{Cureus}

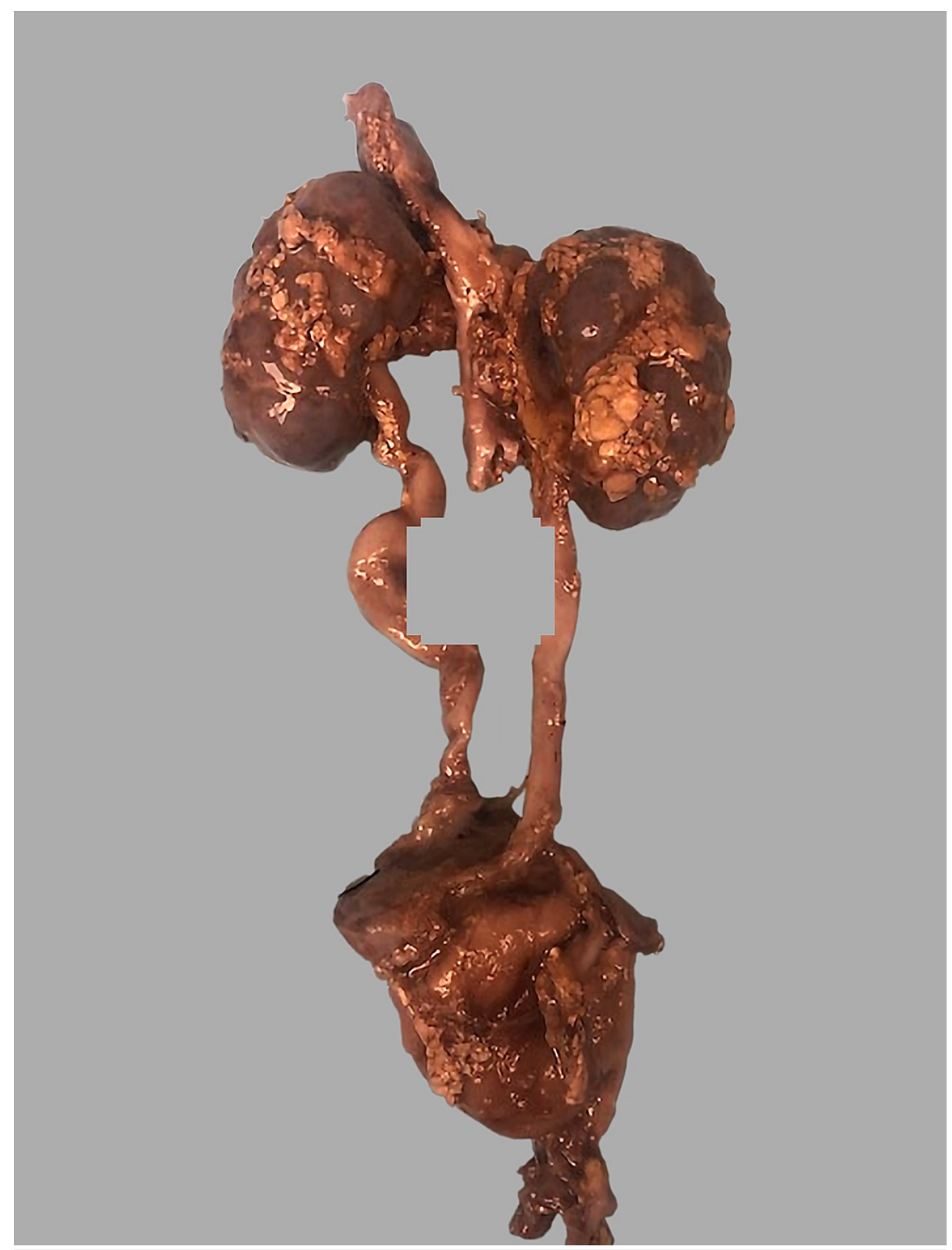

FIGURE 2: Tortuous ureter

\section{Discussion}

The main complication in WS is the obstructive cardiac lesions that result in outflow obstruction. These lesions can be repaired with aortic valve replacement and has been successful even in the middle-aged patients with this diagnosis [6].The majority of the patients present with developmental delay and twothirds of the patients surveyed had cardiac murmur [7]. The condition is associated with a range of linguistic, cognitive, and social issues. The impact of these difficulties becomes evident when this group of patients age, and this increases the risk of social exclusion [8]. Very limited research exists on the educational provision and academic achievements of children with WS, including the non-existing literature on their voices, and doing more research in this area can improve the education and its outcomes [9]. WS is a multisystem disease and cardiac abnormalities are the leading cause of morbidity and mortality in these patients. Cardiovascular abnormalities are the major determining factor in the trajectory of these patients and advances in surgical techniques can improve prognosis [10]. These patients also have tendency to develop hernias, which suggests that they may have some kind of connective tissue disorders [11]. Molecular and genetic studies have indicated that elastin deficiency may be the culprit for cardiovascular and other connective tissue defects in this group of patients [12]. Identifying the genetic alteration pathways and targeting those can change the course of the disease and improve prognosis in these patients [13]. In our case the patient had severe cardiovascular abnormalities. Prenatal echocardiogram showed supravalvular aortic stenosis and pulmonary stenosis. The postnatal course was complicated by feeding difficulties and desaturation. Grossly the heart was hypertrophied with obstructed ventricles and rudimentary, hypoplastic 
aortic root, indicating the primary cause of mortality in the patient. Gross autopsy findings included generalized edema, macrocephaly with short neck, and multiple facial anomalies including mandiblular hypoplasia, depressed nasal bridge, long philtrum, ear malformation, and wide mouth. An enlarged, dilated, and tortuous left ureter was a unique finding to this case, in addition to variation in the renal arteries' size and a small bowel outpouching located $33 \mathrm{~cm}$ from the ileocecal valve.

\section{Conclusions}

In conclusion, a majority of WS cases are sporadic, and few are familial and are inherited as autosomal dominant. Ureteric abnormality seen in this case is extremely rare and it is unclear whether this constitutes a defining feature of this syndrome or not, but worth investigating. Progress in understanding the complex developmental role of the extracellular matrix will likely result in new therapies for the connective tissue abnormalities.

\section{Additional Information \\ Disclosures}

Human subjects: Consent was obtained or waived by all participants in this study. Conflicts of interest: In compliance with the ICMJE uniform disclosure form, all authors declare the following: Payment/services info: All authors have declared that no financial support was received from any organization for the submitted work. Financial relationships: All authors have declared that they have no financial relationships at present or within the previous three years with any organizations that might have an interest in the submitted work. Other relationships: All authors have declared that there are no other relationships or activities that could appear to have influenced the submitted work.

\section{References}

1. Morris CA, Demsey SA, Leonard CO, Dilts C, Blackburn BL: Natural history of Williams syndrome: physical characteristics. J Pediatr. 1988, 113:318-26. 10.1016/s0022-3476(88)80272-5

2. Greenberg F: Williams syndrome. Pediatrics. 1989, 84:922-3.

3. Twite MD, Stenquist S, Ing RJ: Williams syndrome. Paediatr Anaesth. 2019, 29:483-90. 10.1111/pan.13620

4. Nassar MS, Pushparajah K, Bell A, Austin CB: De novo obstruction after supravalvular aortic stenosis repair in Williams-Beuren syndrome. Ann Thorac Surg. 2015, 99:1806-7. 10.1016/j.athoracsur.2014.06.108

5. Morris CA: Introduction: Williams syndrome. Am J Med Genet C Semin Med Genet. 2010, 154C:203-8. 10.1002/ajmg.c.30266

6. Safa K, El Ghazal R: Better late than never: diagnosis and successful treatment in late adulthood of supravalvular aortic stenosis secondary to Williams-Beuren syndrome. Conn Med. 2011, 75:21-3.

7. Nicholson WR, Hockey KA: Williams syndrome: a clinical study of children and adults . J Paediatr Child Health. 1993, 29:468-72. 10.1111/j.1440-1754.1993.tb03023.x

8. Royston R, Waite J, Howlin P: Williams syndrome: recent advances in our understanding of cognitive, social and psychological functioning. Curr Opin Psychiatry. 2019, 32:60-6. 10.1097/YCO.0000000000000477

9. Palikara O, Ashworth M, Van Herwegen J: Addressing the educational needs of children with Williams syndrome: a rather neglected area of research?. J Autism Dev Disord. 2018, 48:3256-9. 10.1007/s10803-0183578-x

10. Collins RT 2nd: Cardiovascular disease in Williams syndrome. Curr Opin Pediatr. 2018, 30:609-15. 10.1097/MOP.0000000000000664

11. Rashid F, Chaparala R, Ahmed J, Iftikhar SY: Atypical right diaphragmatic hernia (hernia of Morgagni), spigelian hernia and epigastric hernia in a patient with Williams syndrome: a case report. J Med Case Rep. 2009, 3:7. 10.1186/1752-1947-3-7

12. Wu YQ, Sutton VR, Nickerson E, et al.: Delineation of the common critical region in Williams syndrome and clinical correlation of growth, heart defects, ethnicity, and parental origin. Am J Med Genet. 1998, 78:82-9. 10.1002/(sici)1096-8628(19980616)78:1<82::aid-ajmg17>3.0.co;2-k

13. Parrish PCR, Liu D, Knutsen RH, Billington CJ, Mecham RP, Fu YP, Kozel BA: Whole exome sequencing in patients with Williams-Beuren syndrome followed by disease modeling in mice points to four novel pathways that may modify stenosis risk. Hum Mol Genet. 2020, 29:2035-50. 10.1093/hmg/ddaa093 